\title{
Formalismo, activismo y discrecionalidad judicial
}

\author{
Judicial Formalism, \\ Activism, and Discretion
}

Formalismo, ativismo e discricionariedade judicial

Juan B. Etcheverry* 


\section{Resumen}

Este artículo busca explicar por qué las expresiones "formalismo" y "activismo" judicial suelen utilizarse como modos antagónicos de descalificar la actividad judicial. Para ello, será necesario aclarar que estas expresiones son usadas con diferentes sentidos en distintos contextos jurídico-profesionales e, incluso, que ellas admiten más de un sentido en un mismo contexto jurídico-profesional. Sin embargo, en esta oportunidad nos concentraremos en dilucidar el sentido peyorativo con que se las utiliza. Aclarado tal sentido, sostendremos que ambas expresiones, en algunos casos, son usadas de un modo descalificativo porque identifican modos de entender la función judicial que no se toman en serio dos elementos básicos (normalmente considerados valiosos) de los sistemas jurídicos occidentales actuales: los derechos fundamentales y las leyes democráticas. Para finalizar, propondremos un modelo alternativo de comprensión de la actividad judicial compatible con dichos elementos.

\section{Palabras clave}

Legalismo; decisionismo judicial; arbitrariedad judicial; control de constitucionalidad; determinación judicial del derecho. 


\section{Abstract}

This article seeks to explain why the terms judicial "formalism" and "activism" are often used as antagonistic ways of discrediting judicial activity. Thus, it will be necessary to clarify that they have different meanings in diverse legal-professional contexts and even carry more than one meaning in the same context. However, this time we will focus on elucidating their pejorative sense. Then, we will argue that both terms, in some cases, are belittling because they identify ways of understanding the judicial function that do not take two essential elements - generally considered valuable - of current Western legal systems seriously: fundamental rights and democratic laws. Finally, we propose an alternative model to understand judicial activity compatible with these elements.

\section{Keywords}

Legal technicality; judicial decisionism; judicial arbitrariness; constitutional review; judicial determination of law. 


\section{Resumo}

Este artigo procura explicar por que as expressões "formalismo" e "ativismo" judicial costumam ser utilizadas como modos antagônicos de desqualificar a atividade judicial. Para isso, será necessário esclarecer que essas expressões são usadas com diferentes sentidos em diferentes contextos jurídico-profissionais e, inclusive, que elas admitem mais de um sentido num mesmo contexto jurídico-profissional. No entanto, nesta oportunidade nós nos concentraremos em dilucidar o sentido pejorativo no qual são utilizadas. Com isso esclarecido, sustentaremos que ambas as expressões, em alguns casos, são usadas de um modo desqualificativo porque identificam modos de entender a função judicial que não levam a sério dois elementos básicos (normalmente considerados valiosos) dos sistemas jurídicos ocidentais atuais: os direitos fundamentais e as leis democráticas. Para finalizar, proporemos um modelo alternativo de compreensão da atividade judicial compatível com esses elementos.

\section{Palavras-chave}

Legalismo; decisionismo judicial; arbitrariedade judicial; controle de constitucionalidade; determinação judicial do direito. 
Sumario: Introducción: “formalismo" y "activismo” como adjetivos calificativos de la actividad judicial. 1. La función judicial: ¿un problema estratégico o de justicia? 2. Los límites de una mirada formalista y de una activista: no se toman en serio a los derechos ni a las leyes. 3. Los límites de todo intento por armonizar leyes y derechos. 4. La determinación judicial del derecho. Conclusión. Bibliografía.

\section{Introducción: "formalismo" y "activismo" como adjetivos calificativos de la actividad judicial}

Las expresiones "formalismo" y "activismo" judicial son dos maneras antagónicas de calificar a la actividad judicial. En algunos contextos jurídicos profesionales (v. g., el argentino, español, estadounidense, etc.) y en determinadas circunstancias son usadas con la finalidad de descalificarlas. ${ }^{1}$ De hecho, muchos de quienes son (des)calificados como "formalistas" se defienden sugiriendo que quienes los critican son "activistas" judiciales y viceversa. Dicho de otra manera, en algunas oportunidades, el uso de estas expresiones se hace con la finalidad transmitir una opinión sobre la actividad judicial, al menos en algunos casos, sobre cómo no deberían actuar los jueces. Sin embargo, este uso descalificativo no es uniforme entre las distintas comunidades jurídicas profesionales. Por ejemplo, el uso descalificativo de la expresión "activismo judicial" ni siquiera ha sido uniforme a lo largo de la historia en una misma comunidad jurídica profesional. ${ }^{2}$

Realizadas estas aclaraciones preliminares, podemos afirmar que el uso peyorativo que algunas comunidades jurídicas profesionales le dan a la expre-

1 Para Atienza, si bien en contextos europeos calificar a un juez como activista tiene un sentido inequívocamente descalificador (es decir, se refiere a que obra como no debería actuar un juez) en otros contextos latinoamericanos (pone el ejemplo de Colombia), esto no necesariamente es así. En otros contextos, calificar a un juez como activista puede querer decir que cumple su función de garantizar los derechos fundamentales (Manuel Atienza, "Siete tesis sobre el activismo judicial", https://dfddip.ua.es/es/documentos /siete-tesis-sobre-el-activismo-judicial.pdf?noCache=1540204326938, consultado el 10 de julio de 2019. Recogiendo este tipo de acepciones, Duquelsky diferencia entre "activismo" y "decisionismo judicial" (Diego Duquelsky Gómez, "La falsa dicotomía entre garantismo y activismo judicial”, Doxa 41 (2018), p. 204). Constitucionalistas argentinos como Santiago si bien reconocen que en el contexto del denominado neoconstitucionalismo se concibe una nueva actitud institucional de los jueces que podría denominarse "activista" y que normativamente se funda en los derechos humanos constitucionalizados, a su vez advierte el riesgo de promover el surgimiento de jueces que se consideren "iluminados o profetas" y que pretendan resolver los problemas sociales y políticos más complejos de una sociedad por medio de un proceso no "diseñado para ello" (A. Santiago, "Sistema jurídico, teoría del derecho y rol de los jueces. Las novedades del neo-constitucionalismo", Dikaion 22 [2008], pp. 140 y 146). Manili distingue entre lo que llaman un activismo "bueno" de uno "malo" (Pablo Manili, "El activismo (bueno y malo) en la jurisprudencia de la Corte Suprema", La Ley, 2006-D-1285). Maraniello, siguiendo a Manili, distingue entre "clases" de activismo: "justo o razonable" e "injusto o arbitrario" (P. A. Maraniello, "El activismo judicial, una herramienta de protección constitucional", Revista de Ciencias Sociales 5 (2010), pp. 54 ss.). Dalla Via ha tratado estos calificativos de la actividad judicial en "Los jueces frente a la política", Isonomía 22 (2005), pp. 19 y ss. Procesalistas como Berizonce hablan de los límites del activismo judicial y de los desafíos que plantea su intervención en las políticas públicas (Roberto Omar Berizonce, "Activismo judicial y participación en la construcción de las políticas públicas", Revista del Instituto Colombiano de Derecho Procesal 36 [2010]). Sobre el uso peyorativo del calificativo "formalista" puede verse Frederick Schauer, "Formalism”, Yale Law Journal 97 (1988), pp. 509-510. Sobre la evolución del uso de la

340 expresión de "activismo judicial" en Estados Unidos ver infra nota 2. Sobre el uso peyorativo de la expresión "formalismo judicial" confrontar infra notas 3 y 4.

2 Sobre la historia del surgimiento del sintagma "activismo judicial", ver Katherine Kmiec, "The origin and the current meaning of judicial activism", California Law Review 92 (2004), passim. 
sión "formalismo" judicial está vinculado con un modo de concebir la función judicial y de aplicar el derecho que entiende al sistema jurídico únicamente como un conjunto de reglas, cuya aplicación ha de llevarse adelante de forma mecánica y solo teniendo en cuenta elementos semánticos, fácticos y lógicos. ${ }^{3}$ Por tanto, sin necesidad de realizar un juicio de valor o de apelar a una interpretación de dichas reglas que tenga en cuenta sus fines, valores o razones subyacentes, que les dan sentido y las justifican. ${ }^{4}$

En cambio, el uso peyorativo que en determinados contextos se le da a la expresión "activismo" judicial suele remitir a un modo de concebir la actividad judicial y de aplicar el derecho que prioriza las opiniones de los jueces acerca de cómo debería resolverse un caso de la forma más justa, incluso por sobre los límites fijados por el propio derecho para resolver ese caso. ${ }^{5} \mathrm{~A}$ esto parecen referirse los autores que vinculan este uso peyorativo del calificativo "activista" con ideas como las de "decisionismo judicial", "jueces iluminados o profetas", activismo "malo", "justiciero", "injusto" o "arbitrario", o "límites o desafíos" del activismo judicial. ${ }^{6}$

Más específicamente, cuando nos referimos al problema de la aplicación de los derechos fundamentales, el uso peyorativo que se hace de la expresión "activismo" judicial parece estar asociado con una manera de aplicar los derechos fundamentales que prioriza la opinión que acerca de su contenido tienen los jueces por sobre una interpretación admisiblemente fundada que realicen de dichos derechos los otros poderes del Estado. ${ }^{7}$

3 Moore define al formalismo como una teoría de la adjudicación, una teoría que se pregunta qué hacen y qué deben hacer los jueces al aplicar estándares a eventos que han ocurrido, teoría vinculada con los ideales que se desprenden del Estado de derecho. Más precisamente, una teoría que considera que el derecho ha de ser aplicado por medio de deducciones lógicas solo con base en estándares jurídicos autoritativos y premisas semánticas y fácticas (Michael Moore, "The Semantics of Judging", Southern California Law Review 54 [1981], pp. 152-167 y 271-273).

4 Una definición de formalismo como "aplicación mecánica" o como "solo seguimiento de reglas" puede encontrarse, entre otros, en Frederick Schauer, "Formalism", The Yale Law Journal 97 (1988), 509-548. Para Schauer, lo que una regla prescribe se encuentra en una relación de causación probabilística con respecto a su justificación. Por ello, inevitablemente, toda norma incorpora supuestos que no sirven a su justificación, a la vez que no incorpora otros supuestos que podrían servir a esta. Estos resultados indeseados e inevitables los ha denominado "experiencias recalcitrantes" y, por ello, solo defiende un formalismo presuntivo y no absoluto (Frederick Schauer, Playing by the Rules, Oxford, Clarendon Press, 1991, p. 54 ss.).

5 Cfr. Manuel Atienza, "Siete tesis sobre el activismo judicial", ob. cit., pp. 3-4

$6 \quad$ Al respecto, ver varios de los autores citados en la nota 1.

7 Esta explicación se asemeja a la que Dworkin utilizó para caracterizar a la clase de "activismo" que, a su juicio, forma parte de lo que llama el "pragmatismo jurídico" (Ronald Dworkin, Law's Empire, Cambridge, Harvard University Press, 1986, p. 378). Sin embargo, unos años antes, en Los derechos en serio, Dworkin defendió un tipo de "activismo" frente a la teoría de la "autorrestricción" (Ronald Dworkin, Taking Rights Seriously, Mass., Cambridge University Press, 1978, pp. 137 y ss.). Dworkin considera que tanto el "pasivismo" judicial (que propone interpretar de un modo "extremadamente estrecho" las cláusulas constitucionales de forma que solo prohibirían lo que su lenguaje incontrovertidamente prohíbe) como el "activismo" virulento (que propone que los jueces interpreten dichas cláusulas solo teniendo en cuenta sus concepciones de justicia y sin considerar si ellas encajan o no en la práctica constitucional entendida como un todo y formada por otros principios como el de equidad en el reparto del poder) no son visiones adecuadas sobre la función judicial y la aplicación del derecho (Dworkin, Law's Empire, ob. cit., p. 378). Algunas formas de pasivismo y de activismo judicial parecen fundar sus propuestas en visiones escépticas sobre los derechos. En cambio, otras versiones del pasivismo judicial creen que los legisladores son capaces de defender mejor los derechos que los jueces. Contra estos argumentos, Dworkin sostiene que la práctica constitucional de Estados Unidos no recepta estas 
En este trabajo no solo buscamos clarificar cuál es el sentido del uso peyorativo de las expresiones "formalismo" y "activismo" judicial, sino principalmente explicar las razones por las que dichas expresiones se usan, al menos en algunas ocasiones, como formas de descalificar la actuación judicial. Al respecto, a continuación sostendremos que ambas son usadas (en algunos contextos) de un modo descalificador porque identifican modos de entender la función judicial que no se toman en serio dos elementos básicos, (normalmente considerados valiosos) de los sistemas jurídicos occidentales actuales: los derechos fundamentales y las leyes democráticas. Finalmente, ofreceremos una mirada alternativa de la función judicial que nos parece que explica, encaja y se puede justificar mejor en el contexto de nuestros sistemas jurídicos occidentales actuales.

\section{La función judicial: ¿un problema estratégico o de justicia?}

Si aceptamos las explicaciones que acabamos de presentar de los usos peyorativos que admiten las expresiones "formalismo" y "activismo" judicial, todavía queda por preguntarnos acerca de las razones para asumir una posición formalista, activista (como se las caracteriza en este trabajo) $u$ otra. ¿Existen razones para justificar que una manera de concebir la actividad judicial y, por tanto, de aplicar el derecho es mejor que otra? En caso de considerar que existen estas razones: ¿de qué tipo son?

$\mathrm{Al}$ respecto, nos parece oportuno (al menos) diferenciar dos tipos de razones para adherir a una u otra posición: las de tipo estratégico y las de justicia. ${ }^{8}$ Expresado en otros términos, cuando criticamos o defendemos una decisión o una actitud judicial calificándola como "activista" o "formalista", con qué criterios o razones lo hacemos. Hacemos esto por el solo hecho de que no coincidimos con lo que finalmente se decidió en un caso en concreto (crítica estratégica que solo busca que se cambie lo decidido) o porque consideramos que es posible pensar un modo de decidir que nos resulte más justo que otros (incluso a pesar de que en algunos casos concretos dicho modo de decidir conduzca a resultados con los que no coincidamos plenamente).

La racionalidad estratégica se define como la elección de aquellas acciones que mejor satisfacen los fines $\mathrm{u}$ objetivos de un individuo, cualesquiera que sean sus características. Es una racionalidad de medios eficientes y, per se, es agnóstica respecto a la naturaleza de los fines a los que sirven los medios. En

ideas (ellas no encajan en dicha práctica). Además, considera dudoso que los legisladores que representan a 342 las mayorías se preocupen por proteger a las minorías, incluso contra las mayorías que los votaron (Dworkin,

8 Schauer advierte el riesgo de un uso peyorativo meramente estratégico de la expresión "formalismo" ("Formalism", ob. cit., p. 510). 
cambio, la racionalidad ética, de la que forman parte las razones de justicia, aspira a mucho más que a la mera tarea de regular la relación entre medios y fines: pretende entender los fines y las razones que los justifican.

De esta distinción puede concluirse que los motivos que mueven nuestra calificación de una decisión judicial como "activista" o "formalista" son de tipo meramente estratégico; en realidad, no nos preocupa tanto el modo en que se decidió o la concepción de la actividad judicial presupuesta en dicha decisión, sino solamente la insatisfacción que genera el resultado de lo que se decidió. Esto supone que esta defensa o crítica tanto del "formalismo" como del "activismo" judicial será solo circunstancial, variable y despreocupada por las razones de justicia que permitirían criticar o justificar diferentes modos de concebir la actividad judicial, la manera en que se decide judicialmente e incluso los resultados de dichas decisiones. En cambio, si nuestra defensa o crítica de estos $u$ otros modos de decidir judicialmente o de concebir la función judicial se basan en razones que consideran que algunos modos de resolver los casos judiciales son más justos que otros (a pesar de que dichos modos no garanticen en todos los casos que se resuelva conforme a lo que uno considera más justo), entonces se aspirará a ofrecerles un fundamento y, por ello, dichas defensas y críticas no serán tan variables y circunstanciales. ${ }^{9}$

\section{Límites de las miradas formalista y activista: no se toman en serio ni los derechos ni las leyes}

Identificados los usos peyorativos de las expresiones "formalismo" $\mathrm{y}$ "activismo" judicial como modos antagónicos de concebir la actividad judicial (uno caracterizado por aplicar mecánicamente el derecho y el otro por priorizar las concepciones personales de los jueces incluso por sobre el derecho), resta todavía el desafío de exponer cuáles pueden ser las razones para defender o criticar las maneras de entender la actividad judicial que presuponen. A nuestro juicio, ambas expresiones son usadas en algunas ocasiones de un modo

9 Tanto el "formalismo" como el "activismo" judicial suelen estar asociados con el "conservadurismo" y el "progresismo" político respectivamente. Sin embargo, en diversos pasajes la historia nos ha enseñado que esto no necesariamente es así. En concreto, el surgimiento histórico de la expresión "activismo judicial" se da en Estados Unidos, a mediados los años cuarenta. Más en concreto, en una época en la que la Corte Suprema comenzó a tener un rol protagónico en el ejercicio de su facultad para controlar la constitucionalidad de las leyes. Específicamente, oponiéndose a la legislación social proveniente de los Estados y del Gobierno Federal. Uno de los primeros antecedentes usualmente catalogados de "activista" es el caso Lochner (1905). En este caso, la Corte Suprema de Estados Unidos declaró inconstitucional una ley del Estado de Nueva York que limitaba la jornada laboral a 10 horas por día de trabajo y a 6 días de trabajo a la semana. Allí, la Corte Suprema consideró que los poderes de policía de los Estados para legislar sobre seguridad, sanidad, etc., no podían vulnerar la libertad de contratación garantizada en la Enmienda 14. Como resulta obvio, esta aplicación del derecho calificada como "activista" difícilmente puede ser considerada, a su vez, como progresista. En la actualidad, son los autores llamados neo-originalistas quienes en su debate con los autores que defienden una lectura moral o una interpretación viva de la constitución recuerdan este tipo de decisiones judiciales y cómo un modo más o menos rígido de entender el sentido de la constitución no supone asumir necesariamente una mirada política conservadora (Lawrence Solum, "Originalism versus living constitutionalism: The conceptual structure of the great debate", Northwestern University Law Review 113 [2019], p. 1268). 
descalificador porque identifican modos de entender la función judicial que no parecen capaces de tomarse lo suficientemente en serio dos elementos básicos (normalmente considerados valiosos) de los sistemas jurídicos occidentales actuales: i) los derechos fundamentales y ii) las leyes democráticas.

En primer lugar, tomarse en serio tanto los derechos fundamentales como las leyes infraconstitucionales supone reconocerles algún contenido susceptible de ser conocido. Dicho de otra forma, tomarnos en serio los derechos fundamentales y las regulaciones legales presupone, al menos, negar que el derecho está radicalmente indeterminado. Negar que dichos derechos y leyes poseen algún contenido susceptible de ser conocido o afirmar que no son capaces en ningún caso de orientar y ordenar la conducta de los jueces y de los ciudadanos (como hacen algunas expresiones del realismo jurídico y de las teorías jurídicas críticas) supone restarles valor, poner en duda su necesidad y relevancia práctica.

En segundo lugar, lo anterior supone introducir una manera diferente de concebir el derecho y la actividad judicial alternativa a la vinculada con el sentido de la expresión "formalismo" judicial que hemos explicado en este trabajo. Esta manera de entender el "formalismo" no parece tomarse en serio los derechos fundamentales. En ocasiones, no acepta que los seres humanos tengan derechos humanos que son reconocidos de diferentes modos por las constituciones y los tratados internacionales. En otras oportunidades, no acepta que el reconocimiento constitucional de dichos derechos suponga el derecho a ser protegido por ellos, incluso contra la mayoría y al precio del interés general. ${ }^{10}$ Una propuesta alternativa, que los tome en serio, no puede considerar, ni que el derecho está formado solo por reglas concretas y determinadas ni que los derechos fundamentales no pueden imponerse contra las mayorías ni que el derecho se aplica mecánicamente o sin valorar o sin preguntarnos por los valores, los objetivos o las razones subyacentes que lo explican y fundamentan.

En tercer lugar, una manera diferente a la "formalista" de entender la actividad judicial y que, a su vez, se tome en serio a las leyes infraconstitucionales, tampoco puede identificarse con el tipo de "activismo" judicial explicado en este artículo. Este "activismo" se caracteriza por defender una manera de concebir la función judicial en la que se prefieren las opiniones de los jueces sobre el modo más justo de resolver un caso, incluso a costa de ignorar completamente el derecho. Suele suceder que los jueces defensores de este tipo de "activismo" buscan justificar su manera de actuar apelando a los derechos fundamentales. Si bien en algunos casos no es fácil establecer cuándo una legislación es contraria a dichos derechos, este "activismo" tampoco se los toma verdaderamente en serio. En realidad, concibe los derechos fundamentales de cada constitución como el fruto de la mejor teoría ideal sobre la justicia con-

10 Cfr. Dworkin, Taking Rights Seriously, op. cit., pp. 138 y 146. 
siderada en abstracto (es decir, sin tener en cuenta el texto, la historia y los objetivos de la práctica constitucional que interpreta). ${ }^{11}$ Por ello, un juez activista (en el sentido que hemos explicado) solo tendrá en cuenta los derechos fundamentales en la medida en que coincidan con su opinión acerca de qué es justo. En caso contrario, intentará manipularlos para que coincidan con su opinión (incluso a costa de vaciarlos de contenido). ${ }^{12}$

En cuarto lugar, si aceptamos que tomarse en serio los derechos fundamentales y las leyes supone buscar un modelo de aplicación del derecho alternativo al "formalismo" y al "activismo" judicial desarrollados, dicho modelo pareciera que tiene que reconocer que el derecho no es completamente determinado ni su aplicación es siempre disyuntiva. Sin embargo, también ha de reconocerse que el derecho no es completamente indeterminado y, por tanto, incapaz de orientar y ordenar, aunque sea de un modo parcial, la decisión de los jueces. Este modelo, por ello, acepta que en algunos casos los jueces deben terminar de concretar o determinar el derecho al resolver los casos.

\section{Los límites de todo intento por armonizar leyes y derechos}

Si bien la mencionada necesidad que tienen los jueces de determinar el derecho para el caso concreto al que lo aplican supone que poseen cierto margen de discrecionalidad sobre algún aspecto de lo que deciden, esto no necesariamente supone que gobiernen los jueces y no la ley, ni que no se tomen en serio a las leyes. Toda vez que los jueces decidan seguir al derecho, conforme al derecho, orientados por el derecho, concretándolo y no contradiciéndolo, estarán mostrando respeto por él, reconociendo su importancia. Así es incluso cuando los jueces aplican una ley apartándose de su significado literal, cuando dicho significado conduce a resultados manifiestamente contrarios a las razones y los principios que las explican y fundamentan. Por ejemplo, la "prohibición de ingresar con vehículos motorizados al parque" no parece razonable que se aplique a quienes por necesidad se desplazan con sillas de ruedas eléctricamente motorizadas. La autoridad que no aplica esta prohibición al caso mencionado no parece mostrarse indiferente o displicente frente al derecho, sino que parece que busca aplicarlo de modo que tenga sentido y resulte coherente. Lo mismo podría decirse de los jueces del reconocido caso Riggs vs Palmer que no permitieron cobrar una porción de una herencia al nieto ingrato que mata a su abuelo con dicha finalidad. ${ }^{13}$

\footnotetext{
11 Cfr. Dworkin, Law's Empire, ob. cit., p. 397.

12 Para Dworkin, los jueces solo deben invalidar la legislación que es contraria a los principios constitucionales, no aquella que se refiere a políticas públicas (policy) sobre cuál es la mejor estrategia para alcanzar algo que es de interés colectivo (v. g., erradicar la pobreza, lograr la seguridad y la salubridad en el trabajo, etc.). (Ibid., p. 398).

13 Ver voto del juez discrepante Gray (Riggs v. Palmer, 115 N.Y. 506 (1889). Traducción al castellano de R. M. Jiménez Cano, J. Fabra y C. Guzmán, Revista Telemática de Filosofía del Derecho 11 (2007/2008), pp. 363-374).
} 
A su vez, la necesidad que en muchos casos tienen los jueces de determinar el derecho no supone que puedan manipular su aplicación para presentarlo como si pudiesen siempre adecuarlo a sus opiniones sobre cuál es la manera más justa de regular y resolver un conflicto. Que los jueces se pregunten por las razones subyacentes y los principios que explican y fundamentan el derecho no quiere decir que puedan manipularlo a su antojo. Dicha manipulación, contraria o no conforme con el derecho, supone un tipo de "activismo" judicial que, como se sostuvo, no se toma en serio ni las leyes ni los principios que las explican y justifican. Un ejemplo de un exceso de este tipo puede encontrarse en algunos de los argumentos de la Sentencia C-141 de 2010 de la Corte Constitucional de Colombia en la que se declara inconstitucional el proyecto de enmienda constitucional que buscaba habilitar la posibilidad de una segunda reelección del presidente de la República. En concreto, la propuesta decía: "Quien haya sido elegido a la Presidencia de la República por dos períodos constitucionales, podrá ser elegido únicamente para otro período". En dicha oportunidad, se esgrimió como uno de los argumentos principales para la mencionada decisión que tal proyecto de enmienda no supondría, en realidad, una reforma constitucional, sino una verdadera sustitución de la Constitución por otra nueva, que no respetaría los principios democráticos y de división de poderes. Coincidimos plenamente con el criterio de los magistrados en que habilitar una segunda reelección para el presidente no es el mecanismo más republicano de distribución del poder. Sin embargo, a nuestro juicio, este tipo de argumentación es un ejemplo del tipo de "activismo" judicial explicado, por medio del cual los jueces impusieron al poder constituyente su opinión acerca de cuál es la forma más justa de organizar el poder; incluso contra un proyecto de enmienda, que no resultaba manifiestamente contrario al resto de la Constitución de la República de Colombia, ni estaba expresamente prohibido por el texto constitucional. ${ }^{14}$

\section{La determinación judicial del derecho}

De lo hasta aquí expuesto se puede concluir que las versiones desarrolladas tanto del "formalismo" como del "activismo" judicial son maneras de concebir la función judicial y, más específicamente, de aplicar el derecho, que los jue-

14 Sentencia C-141/10, c. 6.3.7. Pese a resolver en un sentido diametralmente distinto, calificamos también como "activista" a la sentencia del Tribunal Constitucional de Bolivia que habilita a Evo Morales a presentarse en las elecciones de 2017 para ser reelegido presidente pese a que la Constitución expresamente lo prohibía. En esta oportunidad se apeló a una supuesta contradicción interna entre los preceptos de la Constitución de Bolivia que declaran el derecho a participar en elecciones y aquellos que establecen límites a dicho derecho, en la consideración de que existe una parte de la Constitución con una potencialidad jurídica mayor que el resto de las previsiones (Sentencia constitucional del Tribunal Constitucional Plurinacional de Bolivia 0084/2017). Lo interesante de estos casos es que muestran cómo es posible manipular los textos constitucionales hasta hacerlos decir lo contrario de lo que establecían, cuando no se aceptan las limitaciones que ellos mismos expresamente imponen o dejan de imponer. Sobre cómo ha variado a lo largo del tiempo la regulación de la

346 reelección presidencial en América Latina y sobre cómo los tribunales constitucionales han intervenido en esta cuestión, ver Roberto Viciano Pastor y Gabriel Moreno González, “Cuando los jueces declaran inconstitucional la constitución: la reelección presidencial en américa latina a la luz de las últimas decisiones de las cortes constitucionales", Anuario Iberoamericano de Justicia Constitucional 22 (2018), pp. 165-198. 
ces deben evitar si quieren tomarse en serio al derecho, al menos, como suele entendérselo hoy en día en la mayoría de los sistemas jurídicos occidentales. Este tipo de "formalismo" judicial no se toma en serio a los derechos fundamentales ni a los principios jurídicos y desconoce el valor, sentido y propósito de los preceptos, que es lo que permite explicarlos y justificarlos. A su vez, el "activismo" judicial explicado no se toma en serio las leyes democráticas, pues las desprecia y no las considera obligatorias. En algunos casos, este "activismo" judicial justifica estratégicamente esto al afirmar que estas leyes resultan contrarias a los derechos fundamentales. Sin embargo, dicho "activismo" tampoco se toma en serio los derechos fundamentales, ya que está dispuesto a manipularlos, siempre que su manera de regular la conducta y resolver los conflictos no resulte conforme a lo que considera más justo.

En cambio, el juez que reconoce que el derecho solo está parcialmente indeterminado y que su tarea únicamente supone concretarlo o determinarlo para resolver un caso preciso, se puede tomar en serio tanto los derechos fundamentales como las leyes. Dicho de otra manera, entiende que el derecho se forma por medio un proceso de concreción continuo. Un proceso jurídico que comienza con las normas fundamentales de un sistema jurídico, como su constitución, y sigue por la legislación, su reglamentación, etc., para finalizar con una decisión judicial que aplica todas estas normas para resolver un caso concreto. En dicho proceso, la regla es una concreción/determinación de un principio y, por tanto, cuando se aplica una regla, en realidad se está aplicando también el principio que la fundamenta. ${ }^{15}$ Regla y principio, de este modo, se necesitan mutuamente. La regla precisa del principio para ser correctamente comprendida y fundada, ${ }^{16}$ y el principio de la regla para ser lo

15 La explicación que ofrece Rodríguez-Blanco de la acción de legislar o de decidir judicialmente o de cumplir con las normas, como acciones intencionales que actualizan las capacidades de razonar prácticamente de quienes las realizan, a nuestro juicio resulta compatible con la visión propuesta en este apartado sobre la relación entre las reglas y los principios como partes de un proceso jurídico de determinación continuo. Para Rodríguez-Blanco, una acción intencional es una serie sucesiva de acciones dirigidas a un fin último de la acción (percibido este último como atractivo, conveniente y, por tanto, que posee las características de algo bueno o deseable para hacerse-good-making characteristics-). Dicho fin ilumina y hace inteligible como partes de un todo a la mencionada serie de acciones. Así, la acción intencional es unificada por la intención final que opera como una razón para actuar y puede ser ofrecida a otros como una justificación. A partir de estas ideas, Rodríguez-Blanco afirma que si nuestras acciones intencionales se actualizan por un orden de razones para y en las acciones, y por acciones que se basan finalmente en algo que se concibe como valioso, entonces los legisladores y los jueces necesitan concebir a ese orden de razones como conveniente y capaz de fundamentar sus reglas, directivas y decisiones (Verónica Rodríguez-Blanco, Law and Authority Under the Guise of the Good, Oxford, Hart Publishing, 2014, pp. 35, 45, 58 y 71).

16 La idea de que las reglas tienen una autonomía limitada porque para comprenderlas y justificarlas es necesario hacerlo a la luz de los principios puede encontrarse en Dworkin. Al respecto, defiende que aplicar una norma jurídica supone preguntarse "qué interpretación, de las diferentes interpretaciones admisibles del significado abstracto de un término, mejor desarrollan el conjunto de principios y de políticas públicas capaces de ofrecer la mejor justificación pública para dicha norma al momento de su aprobación" (Ronald Dworkin, "Is there really no right answer in hard cases", en A Matter of Principle, Mass., Harvard University Press, 1986, p. 129). Esta idea fue desarrollada en Taking Rights Seriously, London, Duckworth, 1979, pp. 81 y 107-110, y explicitada en R. Dworkin, Law's Empire, ob. cit., pp. 65-68. Atienza y Ruiz Manero sostienen que los principios cumplen una función explicativa del derecho en dos sentidos: i) permiten sintetizar una gran cantidad de información; y ii) permiten entender al derecho como un conjunto de pautas dotado de sentido (Manuel Atienza y Juan Ruiz Manero, Las piezas del derecho. Teoría de los enunciados jurídicos, Barcelona, Ariel, 2007, pp. 43 ss.) 
suficientemente concreto a fin de poder solucionar problemas de coordinación, y ofrecer un grado de previsibilidad necesario a tal fin. ${ }^{17}$

Es necesario aclarar que la necesidad que tiene la regla de ser comprendida a la luz de uno o varios principios no la vuelve irrelevante, porque ella concreta o determina un modo posible y legítimo (entre otros) de lograr los objetivos propuestos por tales principios. Si bien no hay forma de comprender y justificar lo que manda una regla, si no es por referencia al o a los principios que pretende concretar o determinar ${ }_{1}^{18}$ tal regla es capaz de definir cuál de las distintas concreciones posibles o legítimas de ese o esos principios es la jurídicamente relevante. ${ }^{19}$

En definitiva, los derechos fundamentales son, en principio, determinaciones justas de los derechos humanos. A su vez, las leyes democráticas son, en principio, determinaciones justas de los derechos fundamentales. La legitimidad que les da su origen democrático y la necesidad de que existan las determinaciones que ellas ofrecen justifica la presunción en su favor que la mayoría de los sistemas jurídicos actuales les reconocen. ${ }^{20}$ Fruto de dicha presunción es que quienes alegan su inconstitucionalidad tienen la carga de demostrarla. Por todo esto, cuando los jueces resuelven un caso, no acuden normalmente de forma directa a sus concepciones ideales y abstractas de justicia, sino que lo hacen guiados por las determinaciones jurídicas que se presumen justas y que se encuentran en los principios constitucionales, las leyes democráticas, los reglamentos, los precedentes, etc.

\section{Conclusión}

En síntesis, tomarse en serio tanto los derechos fundamentales como las leyes democráticas presupone aceptar, al menos, siete cosas: 1) que el derecho es una práctica autoritativa que pretende tener la capacidad para orientar y ordenar la conducta tanto de los ciudadanos como de los jueces (y del resto de funcio-

17 Dworkin utiliza una doble distinción que puede ser útil para los fines de lo que se propone en este trabajo entre derechos básicos (background rights) y derechos institucionales, y entre derechos abstractos y concretos. De esta última distinción concluye que los derechos abstractos ofrecen argumentos para los derechos concretos, pero las reclamaciones sobre derechos concretos son más definitivas que las que puedan hacerse sobre los derechos abstractos (Dowrkin, Los derechos en serio, ob. cit., 161 ss.). Más adelante sostendrá que los principios de la dignidad enuncian derechos muy abstractos y que todos los derechos derivan de estos. Ello supone decir que todos los derechos surgen al preguntarnos qué exige la igualdad de consideración y respeto (Ronald Dworkin, Justicia para erizos, Buenos Aires, Fondo de Cultura Económica, trad. de H. Pons, 2014, p. 402).

18 Cfr. Pilar Zambrano, "El derecho como razón excluyente para la acción: una aproximación desde la teoría iusnaturalista de John Finnis", Problema 4 (2010), 336, pp. 358-360.

19 Cfr. Juan B. Etcheverry, “La relevancia del derecho que remite a la moral”, Problema 4 (2010), pp. $233-234$ y "La relevancia de la determinación judicial y la tesis de la respuesta más justa", Dikaion 24 (2015), pp. 66-85.

20 Para un análisis exhaustivo de los argumentos a favor y en contra de la presunción de constitucionalidad de los actos de gobierno ver Manuel José García Mancilla, ¿Presunción de constitucionalidad o presunción de libertad? Un análisis desde el artículo 33 de la constitución nacional, Buenos Aires, Academia Nacional de Ciencias Morales y Políticas, 2014. Si bien dicho trabajo propone varios argumentos para descalificar la mencionada presunción, no aborda el argumento de la necesidad de la determinación legal y reglamentaria del derecho. 
narios); 2) que el derecho pretende orientar la conducta con diversos tipos de preceptos: reglas, principios, estándares, etc.; 3) que tales preceptos tienen diferente jerarquía (v. g., derechos constitucionales y leyes infraconstitucionales), diferente capacidad de explicación y fundamentación del resto de los preceptos y distintos grados de determinación; 4) que el derecho no se puede aplicar mecánicamente o sin valorar o sin preguntarnos por los valores, los objetivos o las razones subyacentes que lo explican y fundamentan; 5) que a los jueces se les ha delegado la tarea de resolver los conflictos "conforme al derecho" y no conforme a sus opiniones sobre cómo se los podría resolver del modo más justo (y sin tener en cuenta el texto de sus preceptos, su historia y la práctica jurídica que los interpreta); 6) tomarse en serio o intentar armonizar derechos fundamentales y legislación democrática supone, a su vez, reconocer que en algunos casos no es fácil establecer los límites de cada uno de ellos sobre el otro, aunque esta tarea no debe concebirse como imposible; y 7) es un presupuesto de la tarea judicial que el derecho está, al menos, parcialmente determinado y que, por tanto, los jueces solo deben concretizarlo o determinarlo aún más para resolver un caso concreto.

\section{Bibliografía}

Atienza, Manuel y Ruiz Manero, Juan, Las piezas del derecho. Teoría de los enunciados jurídicos, Barcelona, Ariel, 2007.

Atienza, Manuel, "Siete tesis sobre el activismo judicial", Ámbito Jurídico, en https:/dfddip.ua.es/es/documentos/siete-tesis-sobreelactivismojudicial. pdf?noCache=1540204326938, fecha de consulta: 10 de julio de 2019 .

Berizonce, Roberto Omar, “Activismo judicial y participación en la construcción de las políticas públicas", Revista del Instituto Colombiano de Derecho Procesal 36 (2010), en http://publicacionesicdp.com/index.php/Revistasicdp/article/view/63

Corte Constitucional de Colombia, Sentencia C-141 de 2010.

Dalla Via, Alberto, "Los jueces frente a la política”, Isonomía 22 (2005), en http://www.scielo.org.mx/scielo.php?script=sci_arttext\&pid $=$ S1405-02182005000100002

Duquelsky, Diego, "La falsa dicotomía entre garantismo y activismo judicial", Doxa 41 (2018), en https://doxa.ua.es/article/view/2018-n41-la-falsa-dicotomia-entre-garantismo-y-activismo-judicial

Dworkin, Ronald, "Is there really no right answer in hard cases", en A Matter of Principle, Cambridge, Harvard University Press, 1986.

Dworkin, Ronald, Justicia para erizos, Buenos Aires, Fondo de Cultura Económica, trad. de H. Pons, 2014. 
Dworkin, Ronald, Law's Empire, Cambridge, Harvard University Press, 1986.

Dworkin, Ronald, Taking Rights Seriously, Cambridge, Cambridge University Press, 1978.

Etcheverry, Juan B. “La relevancia de la determinación judicial y la tesis de la respuesta más justa", Dikaion 24 (2015), en https://dikaion.unisabana.edu. co/index.php/dikaion/article/view/5714

Etcheverry, Juan B. "La relevancia del derecho que remite a la moral", Problema 4 (2010), en https://revistas.juridicas.unam.mx/index.php/filosofiaderecho/article/view/8093

García Mancilla, Manuel José, ¿Presunción de constitucionalidad o presunción de libertad? Un análisis desde el artículo 33 de la constitución nacional, Buenos Aires, Academia Nacional de Ciencias Morales y Políticas, 2014.

Kmiec, Katherine, "The origin and the current meaning of judicial activism", California Law Review 92 (2004).

Manili, Pablo, "El activismo (bueno y malo) en la jurisprudencia de la Corte Suprema", La Ley, 2006-D-1285.

Maraniello, Patricio Alejandro, "El activismo judicial, una herramienta de protección constitucional", Revista de Ciencias Sociales 5 (2010), en https:// dialnet.unirioja.es/servlet/articulo? codigo $=4548361$

Moore, Michael, "The semantics of judging”, Southern California Law Review 54 (1981), en https://heinonline.org/HOL/LandingPage?handle=hein.journals/ scal54\&div $=15 \&$ id $=\&$ page $=$

Rodríguez-Blanco, Verónica, Law and Authority Under the Guise of the Good, Oxford, Hart Publishing, 2014.

Santiago, Alfonso, "Sistema jurídico, teoría del derecho y rol de los jueces. Las novedades del neo-constitucionalismo", Dikaion 17 (2008), en https:// dikaion.unisabana.edu.co/index.php/dikaion/article/view/1400

Schauer, Frederick, "Formalism”, Yale Law Journal 97 (1988), en https://digitalcommons.law.yale.edu/ylj/vol97/iss4/

Schauer, Frederick, Playing by the Rules, Oxford, Clarendon Press, 1991.

350 Sentencia Constitucional del Tribunal Constitucional Plurinacional de Bolivia 0084/2017. 
Solum, Lawrence, "Originalism versus living constitutionalism: The conceptual structure of the great debate", Northwestern University Law Review 113 (2019), en https://scholarlycommons.law.northwestern.edu/nulr/vol113/ iss6/1/

Viciano Pastor, Roberto y Gabriel Moreno González, “Cuando los jueces declaran inconstitucional la constitución: la reelección presidencial en América Latina a la luz de las últimas decisiones de las cortes constitucionales", Anuario Iberoamericano de Justicia Constitucional 22 (2018).

Zambrano, Pilar, "El derecho como razón excluyente para la acción: una aproximación desde la teoría iusnaturalista de John Finnis", Problema 4 (2010). 